\title{
Juvenile Nasopharyngeal Angiofibroma
}

\author{
Ibrahim Irsan Nasution ${ }^{1 *}$, Ajeng Dyah Ayu WP
}

\begin{abstract}
Juvenile nasopharyngeal angiofibroma (JNA) is a rare benign tumour affecting mostly adolescent and can be malignant because it's aggressive, destructive, spread locally and often extends to the skull. The exact cause of JNA is unknown. JNA originates from the pterygopalatine fossa at the aperture of the pterygoid canal. Clinical symptoms include nasal obtruction, epistaxis and headaches. The diagnosis is based on anamnesia, physical and radiological examination. CT scan and MRI are the main modalities in detecting and determining tumour stage.
\end{abstract}

Keywords: Juvenile Nasopharyngeal Angiofibroma (JNA), Tumour, Epistaxis.

Juvenile nasopharyngeal angiofibroma (JNA) adalah tumor pembuluh darah yang langka banyak mengenai usia remaja, bersifat jinak secara gambaran histopatologi tetapi dapat bersifat ganas karena sifatnya yang agresif, destruktif, menyebar lokal dan seringkali meluas ke tulang tengkorak. Angka kejadian berkisar 0,5\% dari semua tumor kepala leher, dengan angka insidensi 1:150.000, dengan frekuensi 0,4 per satu juta penduduk dan angka puncak 3,4 per satu juta penduduk yaitu pada usia remaja di Amerika Serikat. Predileksi kuat JNA pada remaja laki-laki usia 14-15 tahun, walaupun dilaporkan pada rentang usia 10-25 tahun. Perjalanan JNA pada umumnya lambat, gejala biasanya 6-12 bulan sebelum diagnosis ditegakkan, diperkirakan $70 \%$ pasien telah sedikitnya stadium II pada saat diagnosis. ${ }^{1-4}$

\section{PATOFISIOLOGI}

\section{Genetik}

Patofisiologi JNA masih belum jelas. Juvenile nasopharyngeal angiofibroma banyak mengenai

\footnotetext{
* Corresponding author: Email: boimtht@yahoo.com

1 KJFD/KSM Telinga Hidung Tenggorok-Kepala Leher Fakultas Kedokteran Universitas Riau/RSUD Arifin Achmad, Pekanbaru, Riau, Indonesia

2 Fakultas Kedokteran Universitas Riau, Pekanbaru, Riau, Indonesia
}

remaja laki-laki sehingga hal ini mengindikasikan adanya pengaruh endokrin atau hormon sebagai patogenesis. Reseptor androgen, estrogen dan progesteron dan tingginya vascular endothelial growth factor (VEGF) berhubungan dengan inisiasi dan pertumbuhan JNA. Penelitian mengkonfirmasi bahwa sel-sel stroma JNA mengekspresikan vascular endothelial growth factor reseptor-2 (VEGFR2). transforming growth factor beta 1 (TGF Beta 1), dan platelet derrived growth factor (PDGF). Peningkatan ekspresi tersebut menstimulasi proliferasi fibroblas, pertumbuhan endotel dan vaskularisasi tumor oleh mekanisme autokrin. ${ }^{3-7}$ Analisis genetik mengindikasikan hilangnya gen AR pada kromosom Y sebagian atau lengkap dan didapatkannya gen AR pada kromosom $\mathrm{X}$. Kelainan kromosomal yang paling sering terdeteksi adalah gen AR pada kromosom 4,6,8 dan X serta hilangnya gen AR pada kromosom 17, 22 dan $Y^{4-5}$

\section{Histopatologi.}

Juvenile nasopharyngeal angiofibroma adalah tumor berkapsul semu dan terdiri dari sejumlah pembuluh darah dengan lapisan endotel tunggal, tertanam pada stroma kaya kolagen dan fibrosa. Bentuk yang tidak sempurna ini menyebabkan mudah ruptur dan berdarah. Secara makoskopik, gambaran angiofibroma sangat 
tergantung pada komponen penyusunnya yaitu komponen pembuluh darah dan jaringan fibrosa. Gambaran massa sangat bervariasi seperti bertangkai/pedungkel, berlobus, elastis dan berwarna merah muda sampai kelabu. Meskipun secara histopatologi JNA jinak, tetapi JNA memiliki vaskularisasi yang banyak, agresif dan bersifat destruktif. ${ }^{3,5,8,9}$

\section{Penyebaran Lesi Berdasarkan Anatomi}

Lokasi asal mula JNA masih belum diketahui secara pasti. Namun beberapa konsensus menyebutkan JNA berasal dari fossa pterigopalatin pada apertura kanal pterigoid. Sebagian besar tumor tumbuh di submukosa sampai ke nasofaring dan menyebar ke sinus pterigomaxila. Juvenile nasopharyngeal angiofibroma juga mengerosi tulang dan merusak fossa infratemporal, orbital dan fossa kranial. ${ }^{4,5,10-13}$

Penentuan stadium pada JNA umumnya menggunakan sistem klasifikasi Chandler, Fisch dan Radkowski yang dapat dilihat pada tabel 1, 2 dan 3. $1-3,8,14$

Tabel 1. Sistem Klasifikasi JNA Chandler ${ }^{2,3}$

\begin{tabular}{ll}
\hline Stadium & Deskripsi \\
\hline I & Terbatas pada nasofaring \\
II & Meluas ke rongga hidung atau sphenoid \\
III & $\begin{array}{l}\text { Perluasan ke 1 atau beberapa hal berikut: antrum ethmoid, pterigomaxilla dan fossa } \\
\text { infratemporal, orbita dan / atau pipi }\end{array}$ \\
IV & Meluas ke rongga tengkorak \\
\hline
\end{tabular}

Tabel 2. Sistem klasifikasi JNA Fisch ${ }^{1,2,14}$

\begin{tabular}{ll}
\hline Stadium & Deskripsi \\
\hline 1 & $\begin{array}{l}\text { Tumor terbatas pasa nasofaring, terbatas atau sedikit erosi pada tulang foramen } \\
\text { sphlenopalatin }\end{array}$ \\
2 & $\begin{array}{l}\text { Tumor menginvasi fossa pterigoplatin atau maxilla, destruksi tulang sinus ethmoid atau } \\
\text { sphenoid }\end{array}$ \\
$3 \mathrm{a}$ & $\begin{array}{l}\text { Tumor menginvasi fossa infratemporal atau orbita tanpa invasi ke intrakranial } \\
\text { Tumor menginvasi fossa infratemporal atau orbita dengan melibatkan parasellar extradular }\end{array}$ \\
$4 \mathrm{a}$ & $\begin{array}{l}\text { intracranial } \\
\text { Tumor intrakranial intradural tanpa melibatkan sinus kavernosa, fossa ptuitari atau kiasma }\end{array}$ \\
$4 \mathrm{~b}$ & $\begin{array}{l}\text { optic } \\
\text { Tumor intrakranial intradural dengan melibatkan sinus kavernosa, fossa ptuitari atau }\end{array}$ \\
\hline
\end{tabular}

Tabel 3. Sistem klasifikasi JNA Radkowski ${ }^{1-3,8}$

\begin{tabular}{ll}
\hline Stadium & Deskripsi \\
\hline IA & Terbatas pada area hidung dan nasofaring \\
IB & Perluasan pada 1 atau lebih sinus \\
IIA & Perluasan minimal ke fossa pterigopalatina \\
IIB & Perluasan ke fosa peterigopalatina dengan atau tanpa erosi orbital \\
IIC & Perluasan ke fossa infratemporal \\
IIIA & Erosi dasar tengkorak (fossa kranial bagian tengah atau pterigoid) \\
IIIB & Erosi dasar tengkorak dengan ekstensi intrakranial dengan atau tanpa keterlibatan sinus \\
& kavernosa \\
\hline
\end{tabular}




\section{GAMBARAN KLINIS}

Gambaran klinis tergantung dari letak tumor, perluasan dan waktu tumor terdiagnosis. Penyebaran tumor terjadi melalui submukosa dan jaringan lunak disekitar lesi. Umumnya pasien datang dengan gejala klinis obtruksi nasal (80-90\%), merupakan gejala yang paling sering dialami. Epistaksis (45-60\%) sebagian besar unilateral dan berulang. Sakit kepala (25\%) terutama bila sinus paranasal tersumbat dan pembengkakan wajah (10-18\%) dan sebagian besar memiliki riwayat sinusitis kronis. Gejala lainnya adalah hipoestesi pada wajah, perubahan penglihatan, rinore unilateral, anosmia, hiposmia, rinolalia, penurunan pendengaran, nyeri telinga, pembengkakan palatum, dan deformitas pada pipi. $2,3,6,7,10,13,15$

Tanda klinis yang dapat ditemukan yaitu massa di hidung (80\%), massa di mata (15\%), proptosis (10-15\%) dan tanda lainnya termasuk otitis serosa yang disebabkan oleh sumbatan tuba eustachii menyebabkan gangguan pendengaran konduktif, pembengkakan os zigomatikum dan trismus akibat penyebaran tumor ke fossa infratemporal, penurunan penglihatan bila mengenai orbita. ${ }^{1,3,6}$

Pemeriksaan rinoskopi anterior dan endoskopi memperlihatkan permukaan yang rata, rubbery, lobulated, polipoid, kekuningan sampai merah atau ungu, massa hipervaskular berasal dari middle turbinate, ukuran bervariasi, penyebaran dan obtruksi choanal. Pemeriksaan mulut ditemukan palatum sering bergeser ke inferior karena desakan tumor, pada intra oral palpasi dapat ditemukan massa diantara maxilla dan ramus ascending mandibula. Bercak darah dapat terlihat di faring posterior., ${ }^{1,2,4}$

\section{DIAGNOSIS}

Diagnosis JNA ditegakkan berdasarkan anamnesis, pemeriksaan fisik dan radiologis. Biopsi tidak dianjurkan karena meningkatkan risiko perdarahan. Computed Tomography (CT) dan Magnetic Resonance Imaging (MRI) adalah dua modalitas utama yang digunakan dalam mendeteksi dan menentukan stadium tumor tersebut. Selain CT dan MRI, angiografi juga diperlukan dalam menentukan vaskularisasi pada ukuran tumor yang lebih besar dan untuk memungkinkan tindakan embolisasi pembuluh darah untuk mengurangi perdarahan intra operatif. $1,3,4,10,13,16$

Diagnosis JNA penting sekali memahami kekhasan penyebaran tumor dan dapat membedakan dari beberapa lesi lain yang sering muncul di hidung dan nasofaring. Granuloma piogenik dan hemangioperisitoma dapat ditemukan sepanjang nasal dan dihubungkan dengan epistaksis. Tumor lain yang melibatkan basis kranii seperti schwanoma, meningioma, craniopharyngioma, chordoma, kondosarkoma, karsinoma nasofaring, neuroblastoma olfaktori atau rabdiomiosarkoma dapat mirip JNA dengan tingkat lanjut yang terlokalisir., ${ }^{4,17}$

\section{Computed Tomography (CT) scan} menggambarkan sebagian besar tanda radiologi khas dan penyebaran serta destruksi tulang dan ketepatan lokasi tumor. Karakteristik temuan pada CT scan adalah lengkungan anterior dinding maksila posterior (Holman-Miller sign), erosi dasar sinus sphenoid dan penyebaran tumor yang berdekatan dari nasofaring ke sinus sphenoid, invasi ke pterigomaxilla dan infratemporal menyebar melalui fisura orbital inferior, orbita posterior, dan fisura orbita superior. Erosi dan perluasan kanal vidian. . $^{1,-6-6,8,13,18}$

Magnetic Resonance Imaging (MRI) lebih baik dalam menilai gambaran lesi dan penyebaran tumor, khususnya pada kasus yang melibatkan tumor intrakranial yang berbatasan dengan sinus kavernosus dan internal carotid artery (ICA) dan untuk evaluasi lanjutan tumor residual/tumor berulang. Tumor dapat menampilkan gambaran salt and pepper dengan komponen fibrosa tumor berwarna putih dan komponen vaskuler angimatosa berwarna gelap. . $^{1,-6,8,13,18}$

Angiografi adalah metode terbaik dalam memberikan informasi suplai vascular mayor dan untuk embolisasi preoperatif, namun hal ini harus dilakukan 24-48 jam sebelum melakukan reseksi dengan embolisasi. Arterial mayor yang menyuplai tumor-tumor ini adalah ICA ipsilateral yang khas dengan pembuluh darah tambahan Ascending Pharyngeal Artery dan cabang-cabang ICA kavernosa atau sistem carotid eksternal kontralateral. ${ }^{1,4,6,8,13,19}$ 


\section{PENATALAKSANAAN}

\section{Pembedahan dan Embolisasi}

Gold standart tatalaksana JNA adalah pembedahan dengan embolisasi preoperatif. Tambahan modalitas tatalaksana untuk gejala sisa atau JNA rekuren yang dapat diberikan seperti radioterapi, terapi hormon dengan flutamide, cryoterapi, electrokoagulation dan kemoterapi. ${ }^{3,4,9,10,16,19}$ Pendekatan bedah ditentukan oleh usia pasien, perluasan penyakit, tingkat pembedahan (primer atau revisi), vaskularisasi dan keahlian pembedah, peralatan yang tersedia dan penerimaan pasien. ${ }^{1,4,5,13}$

Sebelum dilakukan pembedahan, dapat diberikan terapi anti androgen untuk menyusutkan ukuran tumor. Flutamide merupakan antagonis androgen non steroid, penghantar ke penghambat reseptor kompetitif inhibitor dari testosteron dan dihidotestosteron. Flutamide diberikan selama 6 minggu dengan dosis $10 \mathrm{mg} / \mathrm{KgBB} /$ hari dapat mengecilkan volume tumor sampai 17,2\% (dengan rata-rata penurunan $16,5 \%$, maskimal $40 \%$ ). Efikasi masih terbatas pada pasien post pubertas, tidak efektif pada pasien pre pubertas karena kadar testosteron minimal atau bahkan tidak ada. ${ }^{4,15}$

Embolisasi preoperatif sekarang rutin dilakukan dan bersamaan dengaan gelfoam atau partikel polyvinyl alcohol (PVA) 1-2 hari sebelum operasi. Hal ini dapat menurunkan kehilangan darah intraoperatif sampai $70 \%$ dan meningkatkan area pembedahan sehingga eksisi tumor komplit dapat dicapai. Embolisasi preoperatif biasanya dilakukan sebelum tindakan pembedahan endoskopik. . $^{2,5,17}$ Teknik pembedahan JNA meliputi pembedahan terbuka dan pembedahan endoskopik atau kombinasi. Dapat dilihat pada tabel 4 dibawah ini. 1,2,4,5,17,19,20

Tabel 4. Teknik Pembedahan pada JNA ${ }^{1,2,4,5,17,19}$

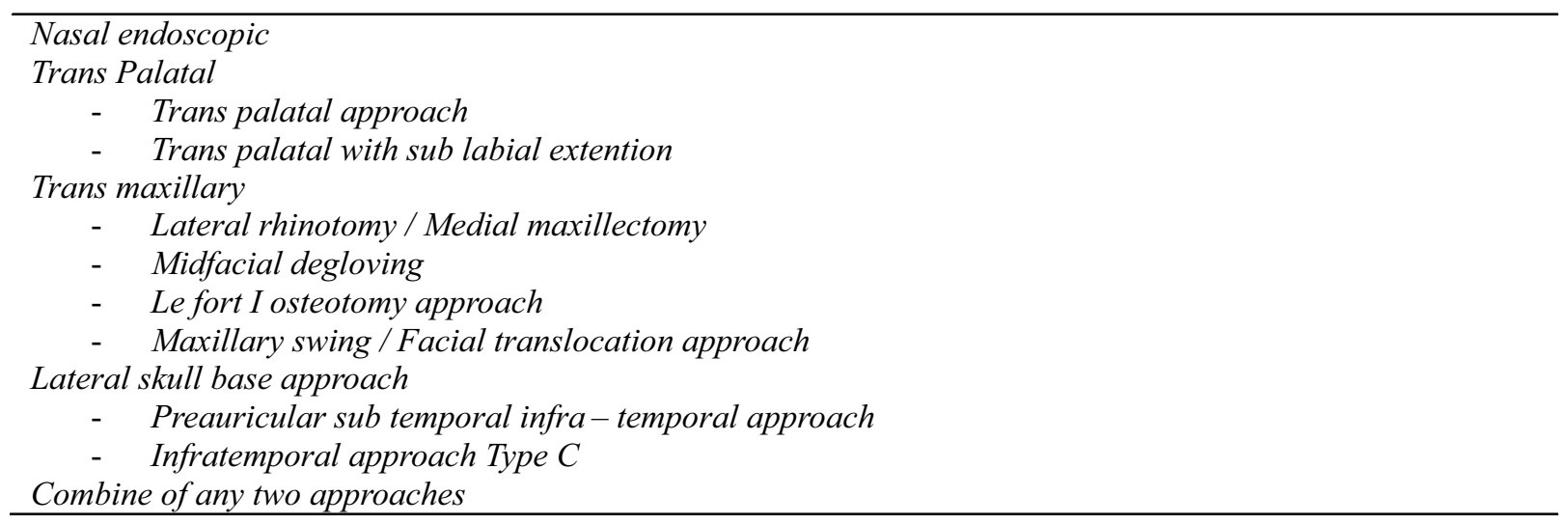

Pembedahan terbuka terbatas untuk ukuran tumor relatif lebih kecil (stadium I,IIa dan IIb), meskipun ahli bedah yang sudah berpengalaman dapat melakukan pada ukuran tumor yang lebih besar. Reseksi endoskopik sangat direkomendasikan untuk tumor stadium awal sampai tumor pada stadiun IIIA-IIIB (berdasarkan klasifikasi Radkowski), hal ini dikarenakan lapangan pandang lebih baik dibandingkan dengan pembedahan lateral rhinotomy, minim perdarahan, minim kebutuhan transfusi darah, durasi operasi lebih singkat, dampak ke pertumbuhan kraniofasial lebih kecil. Kontra indikasi pembedahan endoskopik yaitu pada tumor residual yang meliputi area kritis (ICA, nervus optikus, sinus kavernosa dan dura). ${ }^{1,2,4,5,12}$

\section{Radioterapi}

Pemberian radiasi eksterna pada ANJ efektif sebagai terapi primer pada post pembedahan untuk sisa lesi, pada ukuran tumor yang besar yang diperkirakan tidak dapat direseksi atau pada stadium lokal lanjut, misalnya tumor telah mencapai intrakranial dan melibatkan sinus kavernosus dan kiasma optik. Dosis pemberian radioterapi antara 3046 Gy pada 1,5 sampai 2,3 Gy perterapi, umumnya dosis yang diberikan 30-35 Gy. ${ }^{1,3,4,12,17,20,21}$

Meskipun radiasi dilaporkan efektif sebagai terapi, namun radiasi tidak dianjurkan diberikan pada remaja dengan tumor jinak. Karena komplikasi jangka panjang yang dapat terjadi yaitu transformasi 
maligna, karsinoma tiroid, sarcoma jaringan lunak dan tulang, karsinoma sel basal, hipoptuarism, katarak, atrovi nervus optikum, osteoradionekrosis, osteomiolitis basis cranial, dan retardasi pertumbuhan wajah..$^{1,4,5,20}$

\section{Kemoterapi}

Kemoterapi disarankan pada kasus JNA yang pertumbuhannya agresif dan rekuren. Beberapa kombinasi terapi obat-obat sititoksik seperti dexorubisin dan dacarbazin atau vincristine, dactinomicyn dan cyclophosphamid. Goepfert (dalam Scholfield, et al: 2016) mengatakan bahwa terjadi remisi pada 5 pasien dengan rekurensi JNA menggunakan kombinasi dexorubisin, vincristine, dactinomicyn dan cyclophosphamid, tidak satupun dari kasus dikemudian hari mengalami rekurensi. Penggunaan kemoterapi dalam tatalaksana JA hanya beberapa literature yang menjelaskan. ${ }^{22-24}$

\section{Terapi Hormonal}

Beberapa penelitian mengatakan ada hubungan patogenesis hormone dependen pada JNA. Adanya bukti immunocytochemical reseptor androgen, 75\% menggunakan antibodi terhadap reseptor androgen. Non steroid antagonist androgen, flutamid, menghambat reseptor androgen tanpa efek samping analog estrogen. Namun hanya pada pasien post pubertas. Bevazicumab adalah antibodi monoklonal manusia yang menghambat VEGF-A, tetapi data klinis mengenai terapi ini masih sedikit. Tamoxifen adalah reseptor antagonis estrogen, menghambat proliferasi dari kultur sel stroma JNA. Glukokortikoid dilaporkan dapat menurunkan regulasi VEGF, mereduksi densitas pembuluh darah mikro dan volume tumor. Namun masih belum teruji untuk tatalaksana JNA rekuren atau yang tidak dapat dioperasi. Inhibitor mTOR (mammalian target of rapamycin) sirolimus (rapamycin) dan analognya merupakan inhibitor potensial dari serine/threonine kinase yang mengkontrol proses pertumbuhan sel. B-blocker digunakan pada hemangioma infantile untuk mengurangi ekspresi dari VEGF dan hal ini merupakan teori propanolol menginduksi apoptosis karena keterlibatan dari b1-adrenoreseptor dalam angiogenesis. Antara mTOR dan b-blocker adalah pilihan masa depan dalam tatalaksana JNA. . $2,22,24^{2}$

\section{PROGNOSIS}

Faktor risiko meningkatkan terjadinya rekurensi yaitu usia muda, onset cepat, intensitas tinggi VEGF dan stadium JNA dengan perluasan ke intracranial, erosi dasar tengkorak, melibatkan sinus kavernosus. Rekurensi hasil dari perluasan yang dalam pada tumor menyebabkan jaringan residual setelah operasi. ${ }^{7,25-27}$

\section{SIMPULAN}

Juvenile nasopharyngeal angiofibroma (JNA) adalah tumor pembuluh darah jinak yang langka banyak mengenai laki-laki usia 14-15 tahun. Penyebab terjadinya JNA masih belum diketahui, beberapa referensi mengatakan bahwa endrokin atau hormon sebagai patogenesis. Juvenile nasopharyngeal angiofibroma berasal dari fossa pterigopalatin pada apertura kanal pterigoid. Gambaran klinis tergantung dari letak tumor, perluasan dan waktu tumor terdiagnosis, umumnya gejala yang muncul berupa obtruksi nasal, epistaksis dan sakit kepala. Diagnosis ditegakkan berdasarkan anamnesia, pemeriksaan fisik dan radiologis. CT scan dan MRI sangat membantu dalam mendeteksi dan menentukan stadium tumor. Gold standar penatalaksanaan JNA adalah pembedahan dengan embolisasi preoperatif. Bisa terjadi rekurensi pada JNA.

\section{DAFTAR PUSTAKA}

1. Vuzitas A, Manea C. Juvenile nasopharyngeal angiofibroma - literature review and case series. Romanian Journal of Rhinology. 2018;8:17-24.

2. Butler CR, Scholfield DW, Madani G, Sandison A, Clarke PM. Current management and controversies of juvenile angiofibromas. International Journal of Head and Neck Surgery. 2018;9(1):32-37.

3. Ginting HK, Supriatna N. Angiofibroma nasofaring juvenil. Journal of The Indonesian Radiation Oncology Sociaty. 2018;9(1):28-32.

4. Dewi NM. Tatalaksana juvenile nasopharyngeal angiofibroma. CDK-262. 2018;45:60-6

5. Thakar A, Hota A, Pookamala S. Nasopharyngeal angiofibroma. The 
Otolaryngologist. 2013;6(1):25-34.

6. Tewfik TL, Al Garni MA. Juvenile nasopharyngeal angiofibroma. Medscape. Available from: https://emedicine.medscape.com/ article/872580-overview. [Accessed 28 ${ }^{\text {th }}$ April, 2020]

7. Adham M, Zahara NP, Suroyo I, Lisnawati, Bardosono S. Relationships of radiological and surgical variables and vascular endothelial growth factor expression with reccurence in juvenile nasopharyngeal angiofibroma. Jounal of Physics: Conference Series. 2018;1073:1-9.

8. Wilson MN, Nuss DW, Zachariaa BE, Synderman CH. Surgical management of juvenile nasopharyngeal angiofibroma. Operative Techniques in Otolaryngology. 2019;30:22-9.

9. Alshaikh NA, Eleftheriadou A. Juvenile nasopharyngeal angiofibroma staging: an overview. ENT - Ear, Nose \& Throat Journal. 2015;94(6):12-22.

10.Puran, Kardam MK. Magnetic resonance imaging in evaluation of juvenile nasopharyngeal angiofibroma in term of its diagnosis and pattern of spread. International Journal of Research in Medical Sciences. 2019;7(5):1846-52.

11. Valkov A, Duhlenski B, Tsvetanova K. Modern aproach to juvenile nasopharyngeal angiofibroma: a literature review. International Journal of Science and Research. 2016;5(10):1566-71.

12.Bhalla V, Narayanaswamy R. Juvenile nasopharyngeal angiofibroma: changing paradigms in management. Bengal Journal of Otolaryngology and neck Surgery. 2018;26(1):3542.

13. Rodriguez DP, Orscheln ES, Koch BL. Masses of the nose, nasal cavity,and nasopharynx in children. RadioGraphics. 2017;37:1704-30.

14. Kumar DR, Suresh D, Padmanaban SA. Juvenile nasopharyngeal angiofibroma - a hospital based retrospective study. International Journal of Scientic Study. 2018;6: 82-4.

15. Wheat C, Bickley RJ, Cohen E, Wenzler D, Hunter N, Aztiz D. Juvenile nasopharyngeal angiofibroma presenting with acute airway obtruction. Case Report in Otolaryngology. 2016;10:1-3.
16. Alimli AG, Ucar M, Oztunalii C, Akkan K, Boyunaga O, Damar C, et al. Juvenile nasopharyngeal angiofibroma: magnetic resonane imaging findings. Journal of The Belgian Society of Radiology. 2016;100(1):63,pp 1-8.

17. Safadi A, Schreiber A, Fliss DM, Nicolai P. Juvenile angiofibroma: current management strategies. Journal of Neurology Surgery. 2018;79:21-30.

18. Suroyo I, Budianto T. The role of diagnostic and interventional radiology in juvenile nasopharyngeal angiofibroma: a case report and literature review.

19. Singh ID, Gupta V, Goyal S, Kumar M, Singh A. Endonasal endoscopic technique in management of juvenile nasopharyngeal angiofibroma - our experience. Global Journal of Otolaryngology. 2017;3(4):0088-95.

20. Amdur RJ, Yeung AR, Fitzgerald BM, Mancuso AA, Werning JW, Mendenhall WM. Radiotherapy for juvenile nasopharyngeal angiofibroma. Practical Radiation Oncology. 2011;1:271-8.

21. Mallick S, Benson R, Bhasker S, Mohanti BK. Conformal radiotherapy for locally advanced juvenile nasopharyngeal angiofibroma. Journal of cancer Research and Therapeutics. 2015;11(1):73-77.

22.Lopez F, Triantafyllow A, Synderman CH, Hunt JL, Suarez C, Lund VJ, et al. Nasal juvenile angiofibroma: current perperctives with emphasis on management. International Head and Neck Scientific Group. 2014:1-33.

23. Nicolai P, Schreiber A, Villaret AB. Juvenile angiofibroma: evolution of management. International Journal of Pediatric. 2014:1-11.

24. Scholfield DW, Brundler MA, McDermott AL, Mussai F, Kearns P. Adjunctive treatment in juvenile nasopharyngeal angiofibroma. Journal of Pediatric Hematology/Oncology. 2016;38(3):2359.

25. Acharya S, Naik C, Panditray S, Dany S. Juvenile nasopharyngeal angiofibroma: a case report. Jurnal of Clinical and Diagnostic Research. 2017;11(4):MD03-MD04. 
26.Itoo FA, Iqbal I, Chiesthi L. Juvenile nasopharyngeal angiofibroma: a tertiary hospital - based experience. Indian Journal of Clinical Practice. 2014;25(4): 352-5.
27. Mahmud Sharfuddin, Biswas D, Aich M, Sardar MAR. Management of juvenile nasopharyngeal angiofibroma: a three years retrospective study. Bangladesh Journal Otolaryngol. 2015;2(1):3337. 